\title{
PRONOME: OS CRITÉRIOS NAS GRAMÁTICAS, LIVROS DIDÁTICOS E UMA VISÃO DA CORRENTE FUNCIONALISTA ${ }^{1}$
}

\author{
Janaína de Castro, Universidade Federal de Campina Grande (UFCG) \\ letrasjana@gmail.com \\ Jorgevaldo de Souza Silva, Universidade Federal de Campina Grande (UFCG) \\ jorge.valdo@hotmail.com
}

\begin{abstract}
RESUMO
Este trabalho tem como objetivo geral analisar a interface do pronome, uma das classes gramaticais, fazendo um breve passeio pela história da gramática, mostrando olhares de diversos autores, a exemplo de Bagno (2011) e Bechara (2009), de como cada um trabalha, quais as semelhanças entre esses trabalhos sobre o pronome e quais as diferenças. A análise também situa o leitor nos critérios morfológico, sintático e semântico. Contempla o olhar no material didático do ensino fundamental II e médio, investigando como essa relação do pronome, professor e aluno acontece e se os resultados são eficientes ou se há ajustes a se fazer. Tem-se a proposta voltada para um trabalho com a corrente funcionalista, aqui defendida sob o olhar de Neves (2011). Um aluno graduando, futuro professor e pesquisador tem em suas mãos a língua portuguesa a ser estudada, descoberta, e um material de qualidade o espera dentro dos manuais de linguística, das gramáticas, dos artigos, pesquisas, todos que capacitam, para identificar a melhor maneira de ensinar ao aluno as portas e janelas para compreender o uso da língua portuguesa, da gramática, e em nosso objetivo, o pronome, em especial.
\end{abstract}

PALAVRAS-CHAVE: pronome, gramática, funcionalismo.

\section{INTRODUÇÃO}

Este artigo nasce com a intenção de discutir uma partícula do mecanismo da linguagem, vinda das classes de palavras, o pronome, dentro da língua portuguesa, nos conceitos estudados e aplicados na linha gramatical normativa, discutido em algumas correntes linguísticas e defendido dentro do percurso da corrente funcionalista. Apresenta-se antes um passeio, breve, sobre a gramática.

Segundo Brito (2010), o estudo da gramática inicia-se na língua vernácula, ou seja, a língua local, de forma normativa ou prescritiva. O princípio deste estudo se localiza, pelos

\footnotetext{
${ }^{1} \mathrm{O}$ presente trabalho não contou com apoio financeiro de nenhuma natureza para sua realização.
} 
registros, entre os séculos V e IV a.C., com as primeiras descrições de gramáticos hindus, sobre o sânscrito, e na Grécia clássica, no período alexandrino.

Gurpilhares (2004) faz uma divisão de três períodos principais. Inicia com os présocráticos e os primeiros retóricos e continua com Sócrates, Platão e Aristóteles, quando a língua ainda não era uma preocupação sólida e denota uma importância menor com a língua nesta fase, mais com os aspectos filosóficos. Platão faz um debate sobre a origem da língua, procurando solucionar a dúvida se teria uma relação natural entre a forma da palavra e o seu significado.

No século II a.C., a discussão referente à morfologia da palavra, apresenta uma nova divisão: analogia e anomalia, que tomaram espaço nesta evolução do estudo da língua, em que o requisito era a regularidade, ou seja, se a palavra era regular, estaria na coluna da analogia e caso estivesse irregular, a coluna seria a da anomalia. Nesta disputa entre a analogia versus anomalia, os analogistas criaram modelos de referências, surgindo então o termo paradigma na gramática.

Depois temos o período dos estoicos, no qual a língua passou a ser tratada de maneira mais focalizada em obras independentes. Para os estoicos o estudo da língua eram estudos filosóficos, no qual o homem seria uma "tábula rasa", uma página em branco, preenchida pelas experiências sensoriais e intelectuais de cada indivíduo sendo a língua a maneira de expressar as experiências, logo, para os estoicos, a língua era um veículo de exposição dos pensamentos e sentimentos. Para a classificação das palavras, os gregos usaram um conjunto de critérios que eram os semânticos, os morfológicos e sintáticos.

Em seguida, o período dos alexandrinos se comprometeu em estudar a língua na literatura. Havia dois objetivos, especialmente, que eram tornar acessíveis as obras de Homero e a preocupação de como se usar a língua corretamente, afim de não perder o estilo e características do grego clássico. Foram nomeados alexandrinos por estarem numa colônia grega de Alexandria. Naquela fase, durante os séculos III e II a.C. os sábios daquela região escreveram glossários e compêndios gramaticais.

Coube ao principal discípulo de Platão, Aristóteles, segundo Gurpilhares (2004), introduzir as chamadas "categorias de pensamento" que se tornaram, hoje, objeto de nosso estudo, conhecidas como classes de palavras. Logicamente as classes de palavras não se resumem às estabelecidas por Aristóteles, pois com o passar do tempo foram sendo 
identificadas novas classes de palavras. Dionísio de Trácia criou a primeira definição de gramática grega adicionando às classes de palavras existentes advérbio, particípio, pronome e preposição.

A gramática passou por várias fases distintas, por muitos séculos. Foi aplicada com orientação normativa, algumas mais receptíveis à língua local e à sua variação, entretanto, outras mais prescritivas, ideia essa alheia aos linguistas, que têm interesse no que é realizado e não no que alguns acham que deve ser realizado. Gurpilhares (2004) mostra que a gramática tradicional surgiu como elemento de natureza política e sociocultural, perspectivas essas que até os dias de hoje predominam.

Entre os séculos XIX e início do século XX, as gramáticas eram comparadas e históricas, período no qual havia um domínio pela ideia de história e evolução. O principal motivo para tamanho interesse, em um sentido mais comparatista da língua, segundo Carvalho (1976), se deve à descoberta do sânscrito no século XVII, a partir do qual pode-se comparar e identificar semelhanças entre as gramáticas do sânscrito, grego e latim.

Objetivamos, aqui, compreender, através de análises e reflexões, a definição e uso da classe gramatical pronome, sob a perspectiva de alguns gramáticos, linguistas e ressaltar o olhar do funcionalismo será o objetivo geral deste trabalho. Apresentar o conceito de pronome, como se dá sua classificação, e refletir sob diferentes pontos de vistas entre autores de diferentes correntes linguísticas, classificar o pronome morfológica, sintática e semanticamente e demonstrar a forma como é trabalhada a classe gramatical do pronome nos livros didáticos, nas gramáticas e na corrente linguística do funcionalismo são os pontos a serem contemplados no decorrer do presente texto inserido.

A pesquisa é de cunho bibliográfica e foi fruto de reflexão do material lido nos manuais linguísticos, gramáticas, livros didáticos e artigos que subsidiaram de forma clara e fluente o percurso do presente trabalho, o qual se caracteriza numa abordagem qualitativa, já que busca estudar os casos nos quais os pronomes são utilizados, explorando o comportamento dessa classe gramatical em diferentes situações.

\section{FUNDAMENTAÇÃO TEÓRICA}


A fundamentação teórica desta pesquisa enfatizou o viés do trabalho publicado de diferentes gramáticas, manuais linguísticos, livros didáticos e do funcionalismo, que explica o pronome a partir do seu uso, abordando sua função.

A análise apresentada irá ressaltar o trabalho da linguista Maria Helena de Moura Neves, em seu livro Gramática de Usos do Português, que evidencia o uso do pronome além da estrutura gramatical. Utiliza-se também outras gramáticas de diferentes autores, auxiliando o trajeto de aprendizagem sobre o pronome. Lança-se o olhar de Bagno (2011), com a Gramática Pedagógica do Português Brasileiro na pesquisa, um trabalho que é uma referência para especialistas, e de Bechara (2009), na Moderna Gramática Portuguesa, 37ª edição, atualizada pelo novo Acordo Ortográfico. Nesse espaço, conta-se ainda, nas análises propostas, a abordagem no Manual de Linguística, organizado por Mário Eduardo Martelotta, além da Gramática Resumida de Luft (1987), todos exercendo o método informativo e comparativo.

A pesquisa das classes gramaticais são de extrema importância para que o aluno e o professor possam captar da melhor forma possível e utilizar no cotidiano, seja formal, ou informalmente, o emprego de cada classe. O pronome, abordado nesse trabalho, requer um estudo específico, uma vez que a classe do pronome é dividida em algumas funções e seu emprego se comporta de maneiras diferentes, flexíveis, o que requer um trabalho mais minucioso. Para o ensino fundamental o estudo do pronome é exigido pelos Parâmetros Curriculares Nacional (PCN) e currículo nacional (OCEM), além de estar presente nos livros didáticos, conforme as exigências dos mesmos, valendo salientar que é importante uma investigação de como o assunto está sendo trabalhado, qual a relevância está sendo dada, para que o aluno saia da sala de aula realmente sabendo aplicar o que aprendeu, sendo necessário na etapa de seu ensino médio e para toda a vida.

\section{ANÁLISE}

\section{ANÁLISE DAS GRAMÁTICAS}


Para Bechara (2009), o pronome é uma classe de palavras categoremática, e pode se classificar em pessoais, possessivos, demonstrativos, indefinidos, interrogativos e relativos. Eles se apresentam como absolutos, funcionando como núcleo, ou adjuntos do núcleo.

No discurso, funciona como as duas pessoas, 'eu' e 'tu', onde o 'eu' corresponde ao falante, e o 'tu', ao ouvinte; a terceira pessoa, indeterminada, é outra pessoa em relação aos participantes do ato comunicativo. Semanticamente, os pronomes são como indicadores, determinados ou indeterminados. Os pronomes apontam, direcionam, promovem a dêixis, "o apontar para". Da mesma forma que direcionam, os pronomes também indicam um elemento que consta no texto, onde pode-se exemplificar essa situação com o pronome relativo. Quando o pronome aponta no texto o elemento, esse ato poderá ocorrer de duas maneiras: anafórica ou cataforicamente. Quando a situação for anafórica, significará que o elemento já estará no texto. Quando catafórica, o elemento não terá sido enunciado.

Tratando-se da divisão dos pronomes, será exposto e exemplificado cada um dos tipos de pronome, conforme Bechara (2009). Os pronomes pessoais se apresentam em singular e plural, divididos em primeira, segunda e terceira pessoa, fazendo-se ainda a separação em retos e oblíquos. Para a primeira pessoa, segunda pessoa e terceira pessoa do singular, empregados no caso reto, ter-se-á: eu, tu, ele. Para as três pessoas, igualmente caso reto, mas do plural: nós, vós e eles. A classificação reta diz que esses pronomes estarão se colocando como sujeitos da oração ou frase disposta.

Para cada pronome dos citados acima, do caso reto, haverá o correspondente do caso oblíquo e que se apresentaram de forma átona ou tônica. A forma tônica tem a característica de vir sempre presa à preposição.

Os pronomes do caso oblíquo, singular, átonos, serão: me, te e lhe/o/a/se, que correspondem a, sequencialmente, primeira, segunda e terceira pessoa, ou seja, aos eu, tu e ele, do caso reto, ressaltando que serão trabalhados sem preposição. Os pronomes do caso oblíquo, singular, tônicos, serão: mim, ti e ele/ela/si, correspondendo também as três primeiras pessoas do singular, porém trabalhados com preposição.

Os pronomes do caso oblíquo, plural, átonos, serão: nos, vos, lhes/os/as/se, que correspondem a, sequencialmente, primeira, segunda e terceira pessoa, ou seja, aos nós, vós e eles, do caso reto. Os pronomes do caso oblíquo, plural, tônicos, serão: nós, vós, eles/elas/si, 
correspondendo também às três primeiras pessoas do plural, porém trabalhados com preposição.

Para uma melhor visualização, seguem os exemplos. Nos casos para os pronomes oblíquos, átonos:

- Reportamo-nos ao nosso superior para desculpar o nosso atraso.

Nos casos para os pronomes oblíquos, tônicos:

- As crianças se unem, os adultos brigam entre si.

Apresentada até este ponto, a visão de pronome e especificamente de pronome pessoal, para Bechara (2009), será então agora feito um comparativo com a visão de Neves (2011), referente ao pronome, e continuando, pronome pessoal.

Neves (2011) define o pronome como a palavra usada no local do nome, indicando assim referência pessoal definida. As definições da autora se guiam dentro da perspectiva do discurso, e dentro da escola de Dionísio. Diz-se sobre pronome que um emprego acidental, falando-se aqui de forma figurada, não decidirá sobre uma atribuição de uma palavra na sua determinada classe, ou seja, esse emprego não acontece de forma inflexível.

Continuando a mesma ordem apresentada anteriormente, Neves (2011) divide os pronomes em pessoal, possessivo, demonstrativo, indefinido e relativo. Os pronomes pessoais são apresentados com duas funções básicas: função interacional e função textual. A função interacional garante o papel do discurso na sentença e a textual assegura a continuidade do texto. Além dessas duas funções, há uma terceira: distinguir a natureza temática, do referente.

Neves (2011) utiliza o mesmo princípio de Bechara (2009), quando trata o pronome pessoal dentro da natureza fórica, porém, adiciona a função exofórica (a um dos interlocutores), ou seja, a um item que pertence àquele circuito de comunicação. Um exemplo segue para melhor compreensão:

- Estamos diante da escola e eu estou animada.

Os pronomes pessoais, para Neves (2011), têm o traço de identificar de forma pura a pessoa gramatical. Quando se trata de flexionar o pronome pessoal, em gênero flexiona-se a terceira pessoa do singular e do plural ele/ ela, eles/ elas, observando que também estão flexionadas em número. Exemplos podem ser vistos a seguir:

- Eles estudariam a tarde inteira não fosse a carreata. (Flexionada em número) 
- Ela nasceu na cidade de Floresta Azul. (Flexionada em gênero)

Neves (2011: p. 457) diz que o pronome pessoal tem a função básica de constituir expressões referenciais que representam os interlocutores que se alternam na enunciação, na estrutura formal dos enunciados: primeira pessoa como auto referência, segunda pessoa como aquela a que o locutor se dirige, e terceira pessoa que é a que sobre a qual é o discurso.

Bagno (2011) inicia a unidade que disserta sobre pronome pessoal afirmando que na mesma obra Gramática Pedagógica do Português Brasileiro já explicou porque decidiu não considerar os pronomes como uma classe gramatical, mas sim como uma função que palavras de diferentes classes podem exercer a função anafórica, ou seja, palavra que substitui algum item antes mencionado. Além da função citada, Bagno (2011; p.462) ressalta que o pronome também poderá ser um item que funciona como determinante, como expõe-se nas frases em seguida, com os pronomes demonstrativos:

- Chocolate, eu queria muito viver sem isso.

- Esse caderno é azul!

Bagno (2011) trata o pronome pela ótica do linguista francês Émile Benveniste (19021976), linguista esse que critica a forma tradicional que tratam o pronome. O linguista Émile Benveniste escreve que é necessário, nos pronomes pessoais de primeira e segunda pessoa, por exemplo, um falante pronunciar em seu discurso para a partícula não ser "vazia". Sem dúvida aqui nasceu um novo desafio, uma direção que é diferente das demais tratadas nesse presente trabalho, e que indica o quão rico podem ser a pesquisa e estudo para a análise de uma classe gramatical como o pronome. Uma vez que já foi iniciado sobre os pronomes demonstrativos com Bagno (2011), continuar-se-á o mesmo, agora, com Bechara (2009).

Bechara (2009) define os pronomes demonstrativos como os que indicam a posição dos seres em relação às três pessoas do discurso, uma localização que poderá acontecer dentro dos aspectos de espaço, tempo ou discurso. Na primeira pessoa serão os pronomes este, esta e isto, na segunda pessoa esse, essa e isso e na terceira pessoa teremos aquele, aquela e aquilo. Os pronomes isso, isto e aquilo, no latim, são neutros, e Epifânio Dias os considera como de gênero masculino, pois somente essa definição de gênero cabe à situação, sendo-os invariáveis em gênero e número, característica que também é seguida por Bechara (2009).

Espacialmente os pronomes têm as seguintes denominações: 
- este: está perto de quem fala;

- esse: está longe de quem fala ou perto da pessoa com quem se fala;

- aquele: está distante da primeira e da segunda pessoa.

Também são pronomes demonstrativos: o, mesmo, próprio, semelhante e tal. Mesmo, próprio, semelhante e tal funcionam como pronomes demonstrativos quando exercem identidades, ou se reportam a seres ou ideias já presentes anteriormente na sentença. Mesmo e próprio podem surgir reforçando pronomes pessoais. Um exemplo está na seguinte oração:

- Ela mesma quis comprar o livro.

- Eles próprios chamaram o médico.

Neves (2011) define o pronome demonstrativo como palavra fórica, ou seja, que sempre faz referenciação. Há nessa classificação de demonstrativos exemplos de invariáveis e variáveis, em gênero e número, que se alteram concordando com o substantivo determinado. Da mesma forma que Bechara (2009), cita como invariáveis os pronomes demonstrativos isto, isso e aquilo. Neves (2011) também fala sobre os pronomes demonstrativos que não fazem seleção, conforme segue:

- De pessoa (todos de $3^{\text {a }}$ pessoa): $o, a, o s, a s$;

- De pessoa: tal, tais;

- De pessoa e de número ( $3^{\mathrm{a}}$ pessoa do singular): $o$

O emprego dos pronomes demonstrativos, citados e demais existentes, poderão ser empregados como referenciador textual, como referenciador situacional, de modos, sequencialmente, endofórico e exofórico.

Neves (2011) ressalta que o pronome este não tem a obrigatoriedade de estar próximo: O pronome pode, numa referência anafórica, recuperar a informação que se acha num trecho do texto, relativamente distante.

Bagno (2011), para os pronomes demonstrativos, inicia essa unidade mostrando o pronome $o$ e seu passeio pelo artigo, pronome pessoal e demonstrativo. Lembra, diacronicamente, na classe gramatical latina, que junto de outros pronomes, os quais ele designa como mostrativos, o pronome $o$ se prestava à verificação de identidade. Toda a 
definição e exemplificação em Bagno (2011) se dá numa visão diacrônica para explicar como se dá o uso definições desse pronome, o demonstrativo.

Neves (2011) apresenta através das exemplificações e definiçõos uma ponte que sugere uma visão mais limpa das formas de uso dos pronomes demonstrativos. Utilizando as referências textuais, apontando no sintagma como e porque usar o referido pronome, sugere em suas palavras um percurso que relaciona o trabalho do enunciado, a informação da grade de pronomes disponíveis e como usá-los para cada situação.

O percurso que acontece durante cada gramática, cada autor, para cada classificação do pronome vai mostrando a mesma forma vista até aqui. Entre as classes gramaticais, podese sugerir que há muitas adaptações a serem tomadas para que os alunos e professores possam trabalhar de um modo mais eficiente. Luft (1987) informou, quando fora explicitar a classe gramatical substantivo, que este é a palavra - nome ou pronome, indicando que se pesquise o pronome substantivo. Lembra que o substantivo designa um ser e na frase pode funcionar como sujeito ou objeto direto, e para diferenciar do pronome diz que o substantivo é apenas nome, para que não confunda com pronome substantivo. Para que se entenda a definição e se coloque em uso correto o pronome faz-se necessário a sugestão de um caminho que deixe o estudante ou pesquisador mais seguro.

Neves (2011) utiliza no uso dos textos a ferramenta para facilitar e explicar de uma maneira mais eficiente o uso dos itens lexicais e gramaticais da língua. Acontece no seu trabalho um funcionamento que tem como item a língua viva que leva para a mesa de estudos todas as possibilidades de composição que possam ser aproveitadas no objetivo pedido. Trabalhar o pronome dessa maneira dispõe a possibilidade de um aprendizado mais amplo, que permite uma investigação e exploração mais benéfica nesse percurso, dentro da corrente funcionalista, um recurso que vai além da estrutura gramatical, estudos esses iniciados no Brasil a partir da década de 1980, segundo Martelotta (2015).

\section{ANÁLISE DO MANUAL LINGUISTICO NA CORRENTE DEFENDIDA}

Martelotta (2015) defende que no funcionalismo a linguagem é um instrumento de interação social, que trabalha com dados reais, essencialmente. A linguagem constitui um 
conhecimento específico, complexo, dentro de suas atividades comunicativas. Em resumo ele cita que a língua desempenha funções que são externas ao sistema linguístico em si, e que as funções externas influenciam a organização interna do sistema linguístico. Dentro dessa definição se pode ver que Neves (2011) trabalha as classes gramaticais, aqui especificadas nos pronomes.

Em oposição à corrente linguística que focalizava o estudo da linguagem enquanto expressão do pensamento, os funcionalistas de Praga enfatizaram o caráter multifuncional da linguagem, ressaltando a importância das funções expressiva e conotativa, entre outras, além da referencial. (Martelotta, 2015 p. 161)

A defesa da corrente funcionalista, que Neves (2011) é uma das seguidoras, e que esse trabalho propõe ser um caminho a ter uma boa trilha e chance de sucesso entre aluno e professor mostra o quão amplo é o recurso que essa corrente pode oferecer. Esse trabalho que não ficará preso dentro da sala de aula se faz necessário, podendo ter como resultado o melhor entendimento da gramática e um melhor aproveitamento, uma vez que é funcional, como o próprio título da Escola já traz em seu nome.

\section{ANÁLISE DOS LIVROS DIDÁTICOS}

Para obter uma observação mais cuidadosa de como está sendo abordado a classe gramatical do pronome nos livros didáticos, trabalhou-se três exemplares, dois aplicados em escolas particulares, nas cidades do interior da Paraíba, Cajazeiras e Sousa, dos sexto e sétimo anos do ensino fundamental II, e uma gramática, trabalhada no ensino médio da rede pública da região, na cidade Uiraúna, também estado da Paraíba, todos os livros aplicados durante o período entre 2012 e 2016. No sexto ano a unidade pesquisada pertence ao conjunto de apostilas do Sistema Ari de Sá de Ensino, $4^{\text {a }}$ edição, que funciona em 4 volumes, separados em livros integrados classificados pelos conteúdos, de cada bimestre.

O primeiro para análise, aqui presente, foi visto durante o segundo bimestre, utilizado em 2015. Na seção de Língua Portuguesa, localizado nos capítulos 9 e 10, inicia em uma análise linguística do pronome, e em seguida, no capítulo 10, especifica o conteúdo do pronome, trabalhando os indefinidos, demonstrativos e interrogativos. No capítulo 9, 
exemplifica o pronome com o auxílio do gênero poema, para mostrar os pronomes, uma maneira que fará com que o aluno enxergue desde logo como o pronome está presente no universo da língua portuguesa, fazendo uma análise no poema Canção do Exílio, de Gonçalves Dias.

Define inicialmente o pronome, para Guimarães Júnior (2015), como determinadas palavras da língua que indicam as pessoas do discurso, uma classe de palavras variáveis, participantes do discurso, primeira e segunda pessoa, e seres, eventos ou situações as quais o discurso se refere. Lista os pronomes pessoais, possessivos, demonstrativos, indefinidos, relativos e interrogativos.

Apresenta os pronomes pessoais, pronomes de tratamento e os pronomes possessivos, informando-os e dando exemplos de como são utilizados, sempre trabalhando textos de gêneros diferentes, como o poema, a tirinha, além de algumas sentenças específicas para o que cada item explicativo pede.

Termina o capítulo com os exercícios e o capítulo seguinte, o 10, continua a mesma linha de ensino para os alunos, especificando agora os pronomes indefinidos, demonstrativos e interrogativos.

Quadro 1 - Exemplo dado por Guimarães Júnior (2015) nesta pesquisa

\begin{tabular}{|l|l|l|l|}
\hline Pronome & Tipo & Classificação & Exemplo \\
\hline Que & Interrogativo & $\begin{array}{l}\text { Pronome interrogativo na } \\
\text { frase interrogativa direta }\end{array}$ & O que são meteoros? \\
\hline Qual & Interrogativo & $\begin{array}{l}\text { Pronome interrogativo na } \\
\text { frase interrogativa indireta }\end{array}$ & $\begin{array}{l}\text { Os alunos gostariam } \\
\text { de saber qual o local } \\
\text { escolhido para aula } \\
\text { de campo }\end{array}$ \\
\hline
\end{tabular}

No exemplar do sétimo ano, do ensino fundamental II, no livro didático Para viver juntos: português, a definição de Costa (2014), para pronome, é de que são palavras que substituem ou acompanham nomes, indicando também em uma situação de interlocução, os participantes do ato comunicativo. Serão dados exemplos em sentenças, e listado e explicado os pronomes, seguidos sempre de textos em variados gêneros, como tirinhas, músicas e piadas, ressaltando algumas características a serem trabalhadas como a coesão e a ambiguidade nos pronomes. 
Dois dos exemplos trabalhados por Costa (2014) são: para pronome relativo que, o poema Correção; para o pronome interrogativo que na tirinha Níquel Náusea, de Fernando Gonsales, observa-se: (Exemplos em ordem, na sequência)

Como dizia

Aquele bem-te-vi que ficou míope:

Bem-te-via... bem-te-via...

(José Paulo Paes. É isso ali: poemas adulto-infantojuvenis. São Paulo: Salamandra, 2005.)

O que é isso?

(Sentença retirada da tirinha Níquel Náusea, que mostra o pronome que trabalhado como pronome interrogativo.)

Nos exemplos acima, o pronome relativo é explicado como quando se refere ao termo anterior, ou seja, utilizando apenas o critério sintático, que é o que está na sentença, mas não se fazendo observar, por exemplo, que o pronome não flexiona, logo não é variável, nem comparando com outra oração que possa fazer o aluno refletir o sentido, deixando de lado o trabalho semântico, importante em todos os exemplos e não somente em lugares, do guia de aprendizado, isolados. O pronome interrogativo também é o que, porém, o que faz no livro didático o aluno diferenciar esses dois exemplos que estão postos de forma separada, cada um com sua explicação, é o questionamento colocado, o qual poderia ser discutido no livro de uma maneira mais clara para o aluno.

Os conceitos apresentados pelos autores, trabalhados em definições fechadas, são incompletos, pois não abrangem todos os aspectos dos pronomes, dando aos alunos uma visão limitada para a classe gramatical estudada, ainda deixando algumas lacunas a serem preenchidas. Percebe-se que é como se o pronome não fosse enfatizado nas unidades, como se a passagem por esse estudo fosse mais rápida, e dessa forma fazendo com que a impressão que fique é que poderia ter sido melhor explorado.

Observando e analisando a lista dos exercícios apresentados pelos autores, percebe-se que os mesmos podem ser resolvidos a partir do conceito disponibilizados por eles, mas o critério semântico fica falho, sendo mais enfatizado o critério mórfico e sintático. Pode-se ver também que alguns critérios e exemplos podem deixar o aluno confuso, quando, por exemplo, 
o critério mórfico não tem diferença aparente, utilizados o mesmo vocábulo em classificações distintas.

Lopes (2010), autora da gramática utilizada no ensino médio como o livro didático da língua portuguesa, trabalha no capítulo treze os pronomes, utilizando gêneros como os poemas e as tirinhas de diálogos, para a localização, além das sentenças; observa-se também a semelhança do esquema de explicação mórfico, e sintático, mas não o semântico sendo destacado da mesma maneira.

\section{CONSIDERAÇÕES FINAIS}

O estudo apresentado no presente artigo trabalhou a classe de palavras pronome, percorrendo antes, na gramática, seu estudo histórico, desde o surgimento com os filósofos até a chegada à gramática que trabalhamos atualmente.

A pesquisa identifica que Neves (2011) ao utilizar o discurso facilita a compreensão de forma mais eficaz para o uso dos itens lexicais e gramaticais da língua. $\mathrm{O}$ trabalho do pronome dessa forma disponibiliza uma possibilidade maior de aprendizado pois a corrente funcionalista defende o que vai além da estrutura gramatical, ou seja, é menos restrita na sua explanação.

Os trabalhos feitos no livro didático já levam o aluno, atualmente, para uma limitação, quando consideramos que o pronome, classe à qual está se trabalhando nesta discussão, é apresentado pelo conceito e exemplos, porém não amplamente exemplificado dentro de um discurso mais funcional, como foi observado no exemplar do sétimo ano, do ensino fundamental II, aqui analisado.

As análises feitas com leituras e anotações percorreram Bechara (2009), Bagno (2011) e Neves (2011), além de um breve ponto com Luft (1987), e dois livros didáticos, trabalhados no ensino fundamental II e uma gramática normativa usada no ensino médio. Também utilizados artigos de Gurpilhares e Brito, todo esse estudo propositou o quão é essencial e indispensável o olhar de cada autor para melhor orientar o aluno no cotidiano do aprendizado.

Uma conclusão que ressalta é a defesa da corrente funcionalista que trabalha de forma que abrange o funcionamento da classe no ato comunicativo, além da estrutura. Finalizada a análise das gramáticas e livros didáticos, proposta trabalhada durante todo percurso do 
presente texto, fica claro que os materiais didáticos não trabalham conforme a defesa que se coloca aqui em sugestão para um alcance mais benéfico do ensino e aprendizado.

Fica a proposta da continuidade para que se possa convencer que um material mais completo, dentro da corrente funcionalista, pode ser disponível para que se possa trabalhar em sala de aula, alcançando a compreensão das classes gramaticais, em especial do pronome, que funciona como peça indispensável no cotidiano de todos, no ato comunicativo.

\title{
PRONOUN: THE CRITERIA IN GRAMMARS, TEACHING BOOKS AND A VIEW OF THE FUNCTIONALIST CURRENT
}

\begin{abstract}
The aim of this work is to analyze the pronoun, one of the grammar classes. It considers the teaching material of elementary and secondary education, investigating how the relationship between pronoun, teacher and student. Our proposal is oriented by a functionalist perspective, according to Neves (2011), through points of view of several authors, such as Bagno (2011) and Bechara (2009), and how they particularly deal with the aforementioned topic.
\end{abstract}

Keywords: Pronoun; Grammar; Functionalism.

\section{PRONOME: LOS CRITERIOS EN LAS GRAMÁTICAS, LIBROS DIDÁCTICOS Y UNA VISIÓN DE LA CORRIENTE FUNCIONALISTA}

\author{
RESUMEN
}

Este trabajo tiene como objetivo general analizar el pronombre, una de las clases gramaticales, mostrando miradas de diversos autores, a ejemplo de Bagno(2011) y Bechara(2009) de cómo cada uno trabaja. Se contempla la mirada en el material didáctico de la enseñanza fundamental II y media, investigando cómo es esa relación del pronombre. Se tiene la propuesta volcada hacia un trabajo con la corriente funcionalista, aquí defendida bajo la mirada de Neves (2011).

PALABRAS CLAVE: pronombre, gramática, funcionalismo.

\section{REFERÊNCIAS BIBLIOGRÁFICAS}


BAGNO, M. Gramática pedagógica do português brasileiro. São Paulo: Parábola Editorial, 2011.

BECHARA, E. Moderna gramática portuguesa. 37ªed. rev., ampl. e atual. Rio de Janeiro: Nova Fronteira, 2009.

BRITO, A. M. (Org). Gramática: História, Teorias, Aplicações. Rio de Janeiro: Fundação Universidade do Porto, 2010.

COSTA, C. L. Para viver juntos: português. São Paulo: Ed. SM, 2014.

GUIMARÃES JÚNIOR, A. C. Livro integrado: $\sigma^{\circ}$ ano. 4 ed. - Fortaleza: Sistema Ari de Sá de Ensino, 2015. (Coleção Fundamental)

GURPILHARES, M. S. S. As bases filosóficas da gramática normativa: uma abordagem histórica: Janus, Lorena, ano 1, $\mathrm{n}^{\mathbf{0}} 1,2^{\circ}$ semestre. 2004.

LOPES, K. Nossa língua: códigos, linguagens e suas tecnologias. São Paulo: DCL, 2010.

LUFT, C. P. Gramática resumida: explicação da Nomenclatura Gramatical Brasileira. 9. ed. Porto Alegre: Globo, 1987.

MARTELOTTA, M. E. Manual de linguística. São Paulo: Ed. Contexto, 2015.

NEVES, M. H. M. Gramática de usos do português. 2. ed. - São Paulo: Editoria Unesp, 2011. 